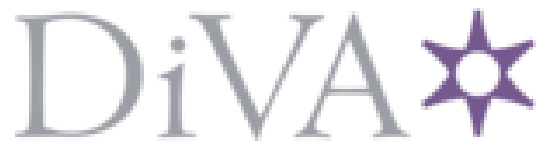

http://www.diva-portal.org

This is the published version of a paper published in Acta Neurologica Scandinavica.

Citation for the original published paper (version of record):

Palstam, A., Westerlind, E., Persson, H C., Sunnerhagen, K S. (2019)

Work-related predictors for return to work after stroke.

Acta Neurologica Scandinavica, 139(4): 382-388

https://doi.org/10.1111/ane.13067

Access to the published version may require subscription.

N.B. When citing this work, cite the original published paper.

Permanent link to this version:

http://urn.kb.se/resolve?urn=urn:nbn:se:du-30205 


\title{
Work-related predictors for return to work after stroke
}

\author{
Annie Palstam (iD | Emma Westerlind (D) | Hanna C. Persson (iD | \\ Katharina S. Sunnerhagen
}

Department of Clinical Neuroscience, Institute of Neuroscience and Physiology, Sahlgrenska Academy, University of Gothenburg, Gothenburg, Sweden

\section{Correspondence}

Annie Palstam, Department of Clinical Neuroscience, Institute of Neuroscience and Physiology, Sahlgrenska Academy, University of Gothenburg, Gothenburg, Sweden.

Email: annie.palstam@gu.se

Funding information

The study was funded by the Swedish Research Council for Health, Working Life and Welfare (FORTE) (grant number 2016-00137), the Swedish Research Council (VR2017-00946), the Norrbacka-Eugenia foundation, the Swedish Brain Foundation, the Swedish Heart and Lung Foundation, the Swedish Stroke Association, the Renee-Eander foundation, and Promobilia, the Swedish government and the county councils, the ALF agreement (ALF71980)

\begin{abstract}
Objectives: Disability due to stroke imposes a large burden on individuals, and on society, in terms of impaired work ability and sick leave. The reported return to work (RTW) rate after stroke varies globally and is influenced by a range of different aspects. The aim of this study was to investigate the influence of work-related factors on time to RTW after stroke, and possible differences between the sexes.

Materials \& Methods: Data from 204 persons with first-time stroke in the years 2009-2010 in Gothenburg, Sweden, who were of working age and had worked prior to their stroke, were analysed. Disease-related characteristics were retrieved from medical records, and work-related- and socio-economic data were collected up to 6 years post-stroke from Statistics Sweden and the Swedish Social Insurance Agency. Cox regression was used to analyse predictors for time to RTW.

Results: We identified qualified occupation and large organizational size as work-related predictors for shorter time to RTW after stroke. Being male predicted a faster and higher frequency of RTW. Qualified occupation predicted shorter time to RTW in men but not in women. For women, the only predictor for RTW was physical dependency at discharge.

Conclusion: Type of work and organizational size are work-related factors of importance for RTW after stroke. Work-related factors were important for RTW in men, but not in women. Reasons for differences between men and women in work-related factors that influence RTW need to be further investigated to better understand how to support women in the RTW process.
\end{abstract}

\section{1 | INTRODUCTION}

Disability due to non-communicable diseases, including stroke, imposes a large burden on individuals as well as on society in terms of work disability and sick leave. ${ }^{1,2}$ In Sweden, 25-30 000 people suffer a stroke each year, of whom $20 \%$ are of working age, an age group in which stroke has become more common in recent years. ${ }^{3}$ As of today, most persons will survive their initial illness, and thus, the health consequences for persons with stroke and their families largely concern various long-term physical, cognitive and emotional disabilities. Stroke is the leading cause of long-term disability in the adult population, with consequences that lead to activity limitations and reduced participation in society, such as prolonged sick leave. ${ }^{4}$

Return to work (RTW) is commonly referred to as the event when resuming work after a period of sick leave. The reported RTW rate has a very large range globally, ${ }^{5-10}$ possibly relating to differences in the social benefit systems and sociocultural aspects in different countries as well as in varying definitions of work. Milder stroke severity and good self-rated health have been reported to be predictors for RTW. ${ }^{6}$ Predictors for no RTW have been reported to be physical dependency at discharge, higher degree of residual disability, ${ }^{11}$ sick leave prior to stroke, ${ }^{9}$ unemployment prior to stroke, ${ }^{12}$ low socio-economic status, ${ }^{8}$ being an immigrant, ${ }^{12}$ comorbidities, ${ }^{12}$ 
older age ${ }^{7}$ and being female. ${ }^{5}$ The odds for RTW have been found to increase in concert with the occupational qualification level, where professionals have the highest odds for RTW compared to workers in elementary occupations and occupations requiring basic skills. ${ }^{5}$ Also, employees working in larger organizations have better odds for RTW than those working in smaller organizations. ${ }^{13}$

In Sweden, sickness benefits are paid by the Swedish Social Insurance Agency, except for the first two weeks of sick leave where the employer provides sick pay. Sickness benefits are approved when a disease is deemed to impair a persons' ability to work by at least $25 \%$ and gradually up to $100 \%$. Decisions on sickness benefits are based on assessments of work ability using criteria that are more stringent when absence from work is prolonged. For persons where no RTW is anticipated due to disease, early retirement in terms of sickness compensation is an alternative arrangement. The employer responsibilities concerning the RTW process of employees' are most explicit in Sweden, although shared with health care, the Social Insurance Office (SIO) and the Employment Agency (EA). Employers are obliged to adapt work tasks, working hours, start work trials, and make technical adjustments, though they are not forced to expand or create new work tasks.

In addition to being a source of income, work also provides a social context and forms an important part of a person's identity. ${ }^{14}$ The drive to reclaim one's life and return to meaningful activities after stroke has been emphasized as a motivational factor for persons with stroke in their RTW process. ${ }^{15}$ RTW has been found to be beneficial for health and well-being after stroke $\mathrm{e}^{16,17}$ and also to be of importance for overall life satisfaction, especially in men, who had a 2.5 times higher risk of being unsatisfied with life if they did not RTW after stroke. ${ }^{18}$ Partially due to the expenses of providing sick leave and disability benefits, stroke constitutes a major socio-economic burden, when considering that it has a relatively high incidence and often results in long-term disabilities and impacts negatively on long-term participation. ${ }^{19}$

\subsection{Aim}

The aim of this study was to investigate the influence of work-related factors on time to RTW after stroke, as well as possible differences between the sexes.

\section{2 | MATERIALS \& METHODS}

\section{1 | Study population}

Patients with first-ever stroke according to the International Classification of Diseases codes 161 intracerebral haemorrhage (ICH), 163 ischaemic stroke (IS) or 160 subarachnoidal haemorrhage (SAH), who were treated either at the Stroke Unit, the Neurosurgical Unit or the Intensive Care Unit at Sahlgrenska University Hospital, Sahlgrenska, Gothenburg, Sweden, and were residing in the Gothenburg urban area, were included consecutively between 4 February 2009 and 2 December 2010 to the
Extended Stroke Arm Longitudinal Study at the University of Gothenburg (SALGOT-extended). ${ }^{20,21}$ In this sub-study, only patients who were of working age (18-63) at stroke onset were included in the analyses. Patients who were registered with sickness compensation prior to their stroke were also excluded from the analyses.

\section{2 | Data collection}

The disease-related characteristics were retrieved from medical records. The mortality rate and cause of death within the study period were retrieved from the mortality register at the National Board of Health and Welfare in Sweden. Information on disability benefits in terms of early retirement and sick leave up to 6 years post-stroke was retrieved from the Swedish Social Insurance Agency. Work-related data and sociodemographic data were retrieved from Statistics Sweden.

\section{3 $\quad$ Return to work (RTW)}

In this study, participants with early retirement prior to stroke onset were excluded from the analyses. Admittance to the hospital with stroke symptoms corresponds to time of entry into the study for each participant. The study period corresponds to the number of days with sickness benefits or sickness compensation post-stroke, as registered by the Swedish Social Insurance Agency. The main outcome was RTW. RTW was defined as no longer being registered on sickness compensation or sickness benefits (either full-time or parttime) with the Swedish Social Insurance Agency after stroke, with the exception of leaving registration within one year from old-age retirement (65 years) or within a month from dying, which was not considered as RTW. Data on sickness compensation and sickness benefits were retrieved from the Swedish Social Insurance Agency.

\subsection{Covariates}

Functional dependency at discharge from hospital was assessed with the modified Rankin Scale (mRS, 0-6, lower score is better). ${ }^{22}$ Data were retrieved from medical records.

Educational level was categorized into three levels: $\leq 9$ years of education, 10-12 years of education and $>12$ years of education. Data were retrieved from Statistics Sweden.

Disposable income is presented in tens of thousands of Swedish crowns (SEK) and corresponds to the individual component of the total household income. Data were retrieved from Statistics Sweden.

Occupational qualification level was categorized into professional occupations and elementary occupations. Data were retrieved from Statistics Sweden.

Size of organization where employed was categorized into four categories: organizations with 1-249 employees, organizations with 250-1999 employees, organizations with 2000-19 999 employees and organizations with $>20000$ employees. Data were retrieved from Statistics Sweden. 
Employment sector was categorized into public or private sector. Data were retrieved from Statistics Sweden.

\section{5 | Statistics}

Data were analysed using the Statistical Package Software for the Social Sciences (SPSS version 22.0, Chicago, IL, USA). All tests were two-sided, and $P$-values $<0.05$ were considered significant. For graphical presentation of time to RTW, Kaplan-Meier curves were used. The log-rank test was used to analyse differences between groups in Kaplan-Meier curves. Multiple Cox proportional hazard model was used to analyse predictors for time to return to work. Variables were included in the model based on clinical and theoretical relevance. Causes for censoring were death, and old-age retirement, during the study period. Participants who died before RTW during the study period were set to censoring at the end of the study period, instead of at the time of death, to get a more conservative estimate for RTW. Censoring due to old-age retirement was set at the time of retirement. To check for serious violations against the proportional hazard assumption of the Cox regression model, Kaplan-Meier curves and log(-log(survival curves)) were used. To check for multi-collinearity, Spearman correlation analysis was performed. To check for outliers, log transformation was used.

\section{3 | RESULTS}

\section{1 | Characteristics}

In total, 249 persons from the SALGOT-extended cohort were of working age (18-63) at the time of stroke, of whom 204 were not receiving sickness compensation prior to their stroke and were included in the analyses. Baseline characteristics of the study population are presented in Table 1, and $12.6 \%$ received reperfusion treatment.

\subsection{RTW}

Out of the 204 persons included in the study, 152 (74.5\%) RTW within the study period, 15 (7.4\%) deceased before RTW, 10 (4.9\%) went into old-age retirement and 27 (13.2\%) were still on sickness compensation at the end of the study period.

Out of the 152 persons who RTW within the study period, 99 (48.5\%) RTW within one year, and after two years, 123 (60.3\%) had RTW. In just over three years, all 152 (74.5\%) had RTW. The RTW rate over different occupational groups is displayed in Figure 1.

When analysing women and men separately, the percentage of men RTW was $77.2 \%$ and the percentage of women RTW was 69.1\%. The mean time to RTW for men was 22.6 (SD 2.3) months, and for women 29.9 (SD 3.5) months, although the difference between groups was not significant $(P=0.091)$, see Figure 2 .

When dividing the population according to functional dependency at discharge, women and men who were functionally independent appeared to RTW in a similar pattern $(P=0.710)$, see
TABLE 1 Characteristics of the study population and comparisons between men and women $(n=204)$

\begin{tabular}{|c|c|c|c|}
\hline Characteristics & Men & Women & p-value \\
\hline Total, $n$ & 136 & 68 & 0.007 \\
\hline $\begin{array}{l}\text { Age at time of stroke, } \\
\text { years median (min-max) }\end{array}$ & $53(24-63)$ & $48(21-63)$ & \\
\hline \multicolumn{4}{|l|}{ Stroke type, $n(\%)$} \\
\hline Ischaemic stroke & $101(74.3)$ & $34(50.0)$ & \multirow[t]{3}{*}{0.002} \\
\hline $\begin{array}{l}\text { Intracerebral } \\
\text { haemorrhage }\end{array}$ & $22(16.2)$ & $17(25.0)$ & \\
\hline $\begin{array}{l}\text { Subarachnoidal } \\
\text { haemorrhage }\end{array}$ & $13(9.6)$ & $17(25.0)$ & \\
\hline \multicolumn{4}{|c|}{ Functional dependency at discharge (mRS), $n$ (\%) } \\
\hline Independent (0-2) & $75(55.1)$ & $33(48.5)$ & \multirow[t]{2}{*}{0.377} \\
\hline Dependent (3-6) & $61(44.9)$ & $35(51.5)$ & \\
\hline \multicolumn{4}{|l|}{ Education level, $n$ (\%) } \\
\hline$\leq 9$ years & $31(23.0)$ & $13(20.0)$ & \multirow[t]{3}{*}{0.466} \\
\hline $9-12$ years & $59(43.7)$ & $27(41.5)$ & \\
\hline$>12$ years & $45(33.3)$ & $25(38.5)$ & \\
\hline $\begin{array}{l}\text { Disposable income (SEK), } \\
\text { median (min-max) }\end{array}$ & $\begin{array}{l}23.0 \\
(0-110.5)\end{array}$ & $\begin{array}{l}18.7 \\
(4.8-143.9)\end{array}$ & 0.008 \\
\hline \multicolumn{4}{|c|}{ Occupational qualification level, $n$ (\%) } \\
\hline $\begin{array}{l}\text { Professional } \\
\text { occupations }\end{array}$ & $65(51.2)$ & $35(54.7)$ & \multirow[t]{2}{*}{0.759} \\
\hline $\begin{array}{l}\text { Elementary } \\
\text { occupations }\end{array}$ & $62(48.8)$ & $29(45.3)$ & \\
\hline \multicolumn{4}{|c|}{ Size of organization where employed, $n$ (\%) } \\
\hline 1-249 employees & $53(46.1)$ & $13(22.0)$ & \multirow[t]{4}{*}{0.001} \\
\hline 250-1999 employees & $17(14.8)$ & 9 (15.3) & \\
\hline $\begin{array}{l}\text { 2000-19999 } \\
\text { employees }\end{array}$ & $26(22.6)$ & $18(30.5)$ & \\
\hline$>20000$ employees & $19(16.5)$ & $19(32.2)$ & \\
\hline \multicolumn{4}{|l|}{ Employment sector, $n$ (\%) } \\
\hline Public sector & $52(40.9)$ & $40(62.5)$ & \multirow[t]{2}{*}{0.006} \\
\hline Private sector & $75(59.1)$ & $24(37.5)$ & \\
\hline
\end{tabular}

Missing values: Education level $(n=4)$, Occupational qualification level $(n=13)$, Size of organization where employed $(n=30)$, Employment sector $(n=13)$.

mRS: modified Rankin Scale; SEK: Swedish crowns.

Bold numbers represent the $p$-values that are statistically significant $(p<0.05)$

Figure 3A. Men who were functionally dependent at discharge appeared to be more likely to return to work, and to RTW faster, than women who were functionally dependent, see Figure 3B. However, the difference between groups was not significant $(P=0.098)$.

\section{3 | Predictors for time to RTW}

In the multivariable Cox regression model 6 years post-stroke, having a qualified occupation and being employed in a large organization were work-related factors that predicted shorter time to RTW when 


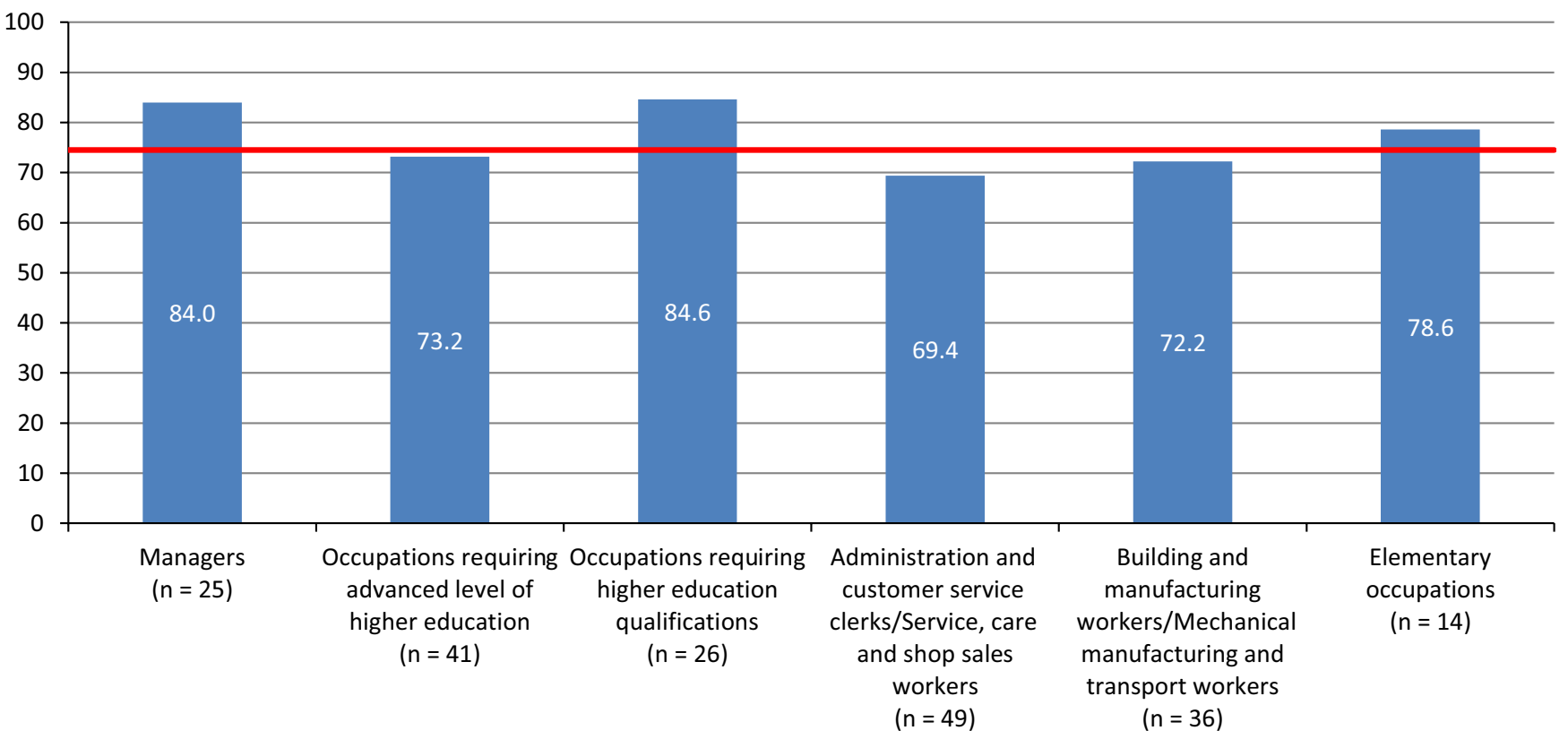

Missing values: $\mathrm{n}=13$

FIGURE 1 Return to work rate after stroke over different occupational groups

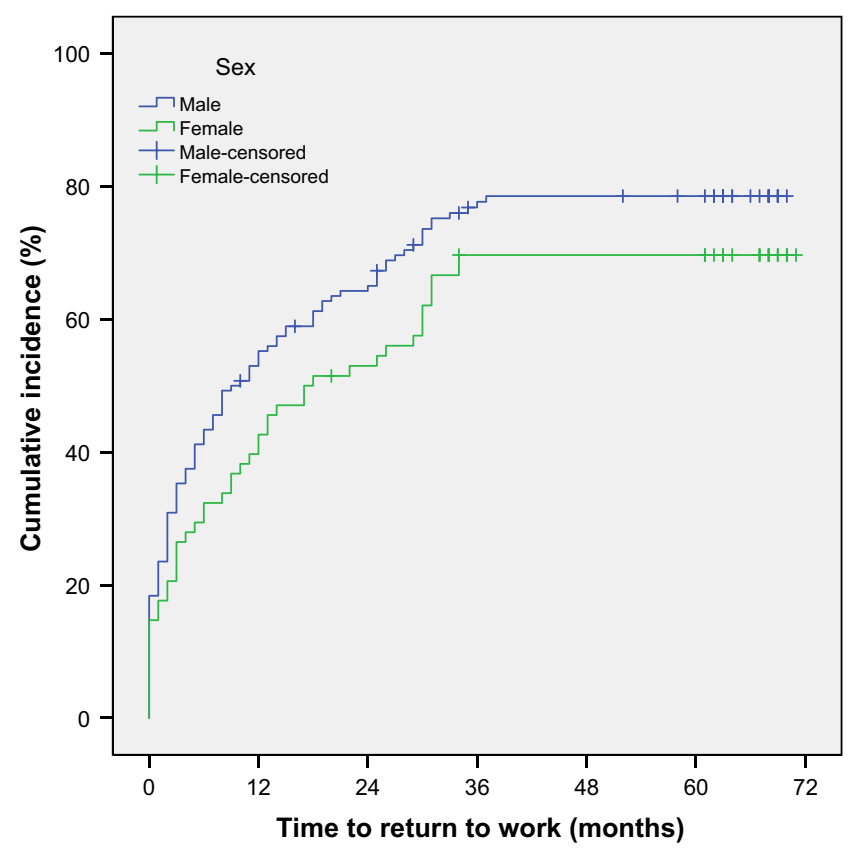

FIG URE 2 Cumulative incidence in time to return to work after stroke, stratified by sex

adjusted for age, sex, functional dependency at discharge and educational level, see Table 2.

Being male was found to be a predictor for shorter time to RTW, see Table 2. When analysing women and men separately, the only work-related predictor for shorter time to RTW in men was found to be having a qualified occupation, along with being physically independent at discharge and having a lower educational level, see Table 3.

For women, no work-related predictors were found and the only factor in the model that could predict shorter time to RTW was being physically independent at discharge, see Table 3 .

\section{DISCUSSION}

We identified having a qualified occupation and working in a large organization as work-related predictors for shorter time to RTW after stroke, based on data from the Social Insurance Agency. Men were more likely to RTW and being male predicted a shorter time to RTW. There were differences in work-related predictors for RTW between the sexes, where having a qualified occupation predicted a shorter time to RTW in men but not in women.

The results showed that occupational qualification level prior to stroke was beneficial for RTW after stroke. This finding is in line with previous literature reviews based on self-reported RTW. ${ }^{10,11}$ Further, the RTW varied depending on occupational groups. The highest RTW rates were found in managers and in occupations requiring higher education qualifications. The lowest RTW rates were found in occupations involving service, care and shop sales work. Similar patterns in RTW rates distributed over these occupational groups have been described previously concerning selfreported RTW. ${ }^{24}$ However, reasons for the distribution remain unclear. Lower chances for successful RTW in a general population based on national registry data were shown when characteristics 

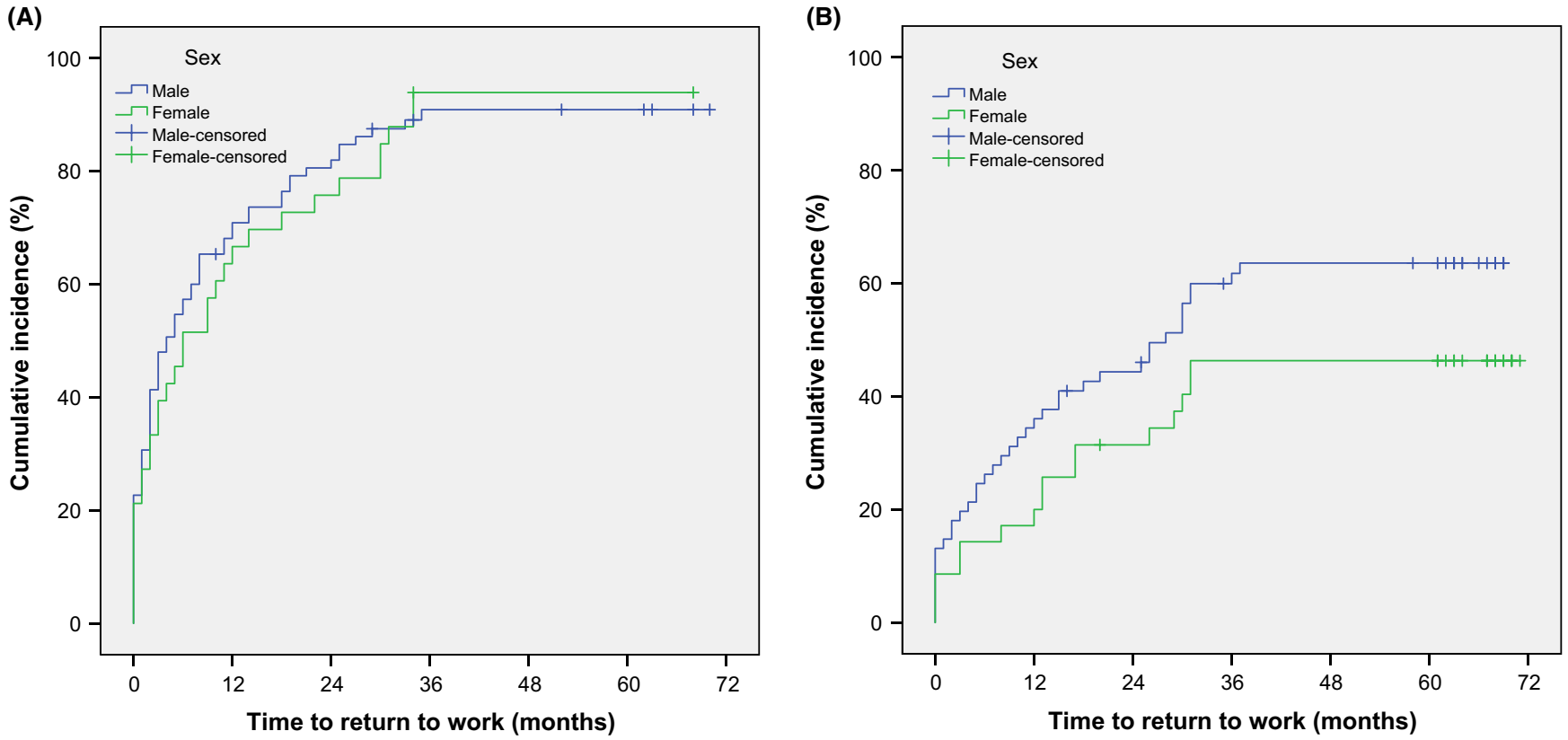

FIGURE 3 A, Cumulative incidence in time to return to work for persons who were physically independent at discharge from hospital after stroke, stratified by sex. B, Cumulative incidence in time to return to work for persons who were physically dependent at discharge from hospital after stroke, stratified by sex

TAB LE 2 Multivariable Cox regression 6 years post-stroke in the total study population $(n=169)$

\begin{tabular}{|c|c|c|c|}
\hline Predictors for time to RTW & HR & $95 \% \mathrm{Cl}$ & $\mathrm{p}$-value \\
\hline Age & 0.975 & $0.953-0.997$ & 0.026 \\
\hline Sex (male) & 1.566 & $1.041-2.355$ & 0.031 \\
\hline \multicolumn{4}{|l|}{ Educational level } \\
\hline$\leq 9 y$ & & & 0.029 \\
\hline $9-12$ y & 0.723 & $0.441-1.183$ & 0.197 \\
\hline$>12 y$ & 0.449 & $0.246-0.821$ & 0.009 \\
\hline Disposable income & 1.012 & $0.998-1.027$ & 0.081 \\
\hline $\begin{array}{l}\text { Functional dependency at } \\
\text { discharge (physically } \\
\text { independent) }\end{array}$ & 3.986 & $2.680-5.928$ & $<0.001$ \\
\hline $\begin{array}{l}\text { Occupational qualification } \\
\text { level (qualified occupation) }\end{array}$ & 1.859 & $1.198-2.884$ & 0.006 \\
\hline \multicolumn{4}{|c|}{ Size of organization where employed } \\
\hline 1-249 employees & & & 0.042 \\
\hline 250-1999 employees & 0.848 & $0.469-1.532$ & 0.584 \\
\hline 2000-19 999 employees & 1.766 & $1.039-3.003$ & 0.036 \\
\hline$>20000$ employees & 1.874 & $0.901-3.900$ & 0.093 \\
\hline Employment sector (public) & 0.699 & $0.392-1.244$ & 0.223 \\
\hline
\end{tabular}

Bold numbers represent the $p$-values that are statistically significant $(p<0.05)$

of work demands and functional impairments overlap, where persons with psychological diagnoses had particular difficulties in RTW to occupations with psychologically demanding work, and persons with musculoskeletal diagnoses had particular difficulties in RTW to occupations with physically demanding work. ${ }^{25}$ One could argue that occupations involving service and care offer less flexibility regarding workplace adjustments than, for example, occupations involving managerial work tasks and could therefore be an explanation for the different RTW rates in different occupational groups.

To be employed in an organization of larger size seemed to be beneficial for RTW, which is in line with a previous literature review based on self-reported RTW. ${ }^{13}$ This could indicate that larger organizations have better systems, more experience and resources to rehabilitate employees back to work. ${ }^{26}$ However, the Swedish legislation regarding the extensive employer responsibilities in the RTW process means good support for employees regardless of workplace.

Our results support the use of sex as a valuable predictor for RTW, with men being more likely to RTW, which has been shown concerning self-reported RTW as well as RTW based on data from national registries. ${ }^{5,10,27,28}$ However, men and women were functionally independent at discharge RTW in a similar pattern. Contrary to this, when physically dependent at discharge, men appeared to have better chances for RTW than women. Previous findings on RTW in men and women have also indicated gender differences, where women with illness-restricted activity prior to stroke were found to have lower chances for self-reported RTW within one year post-stroke, compared to men with illness-restricted activity prior to stroke. ${ }^{27}$ Another gender difference found in our study was that men benefitted from being employed in qualified occupations, while women did not. The gender differences in the RTW process after stroke could be related to the segregated labour market where different working conditions in typical female-dominated occupations as compared to typical 
TABLE 3 Multivariable Cox regression model 6 years post-stroke stratified by sex

\begin{tabular}{|c|c|c|c|c|}
\hline \multirow{2}{*}{$\begin{array}{l}\text { Predictors for time to } \\
\text { RTW }\end{array}$} & \multicolumn{2}{|l|}{ Men $(n=111)$} & \multicolumn{2}{|l|}{ Women $(n=58)$} \\
\hline & $\mathrm{HR}(95 \% \mathrm{Cl})$ & p-value & $\mathrm{HR}(95 \% \mathrm{Cl})$ & p-value \\
\hline Age & $0.982(0.955-1.010)$ & 0.210 & $0.958(0.918-1.000)$ & 0.051 \\
\hline \multicolumn{5}{|l|}{ Educational level } \\
\hline$\leq 9 y$ & & 0.049 & & 0.070 \\
\hline $9-12$ y & $0.566(0.314-1.022)$ & 0.059 & $1.654(0.581-4.707)$ & 0.345 \\
\hline$>12 y$ & $0.399(0.189-0.843)$ & 0.016 & $0.635(0.190-2.124)$ & 0.461 \\
\hline Disposable income & $1.015(0.995-1.036)$ & 0.152 & $1.011(0.984-1.040)$ & 0.427 \\
\hline $\begin{array}{l}\text { Physically independent } \\
\text { at discharge }\end{array}$ & $3.346(2.030-5.515)$ & $<0.001$ & $6.080(2.635-14.031)$ & $<0.001$ \\
\hline Qualified occupation & $2.065(1.192-3.578)$ & 0.010 & $1.169(0.464-2.943)$ & 0.740 \\
\hline \multicolumn{5}{|c|}{ Size of organization where employed } \\
\hline 1-249 employees & & 0.095 & & 0.399 \\
\hline 250-1999 employees & $0.790(0.384-1.621)$ & 0.520 & $0.956(0.260-3.511)$ & 0.946 \\
\hline $\begin{array}{c}\text { 2000-19999 } \\
\text { employees }\end{array}$ & $1.648(0.902-3.011)$ & 0.104 & $2.164(0.602-7.783)$ & 0.237 \\
\hline >20 000 employees & $1.986(0.788-5.010)$ & 0.146 & $1.161(0.258-5.223)$ & 0.846 \\
\hline $\begin{array}{l}\text { Employed in public } \\
\text { sector }\end{array}$ & $0.700(0.340-1.441)$ & 0.333 & $1.135(0.359-3.587)$ & 0.830 \\
\hline
\end{tabular}

male-dominated occupations mean less flexibility and possibilities for adjustments and contributes to an overrepresentation of women registered with sick leave in the Swedish Social Insurance Agency.

A limitation of this study is the missing data on occupational information. This is related to the system where work-related data are reported yearly by all employers in Sweden to Statistics Sweden, and employers' failure to report this data results in missing data. Another limitation is that the Swedish Social Security system allows for part-time sick leave and part-time disability benefits although in this study we have defined RTW as no longer being registered with the Swedish Social Insurance Agency to any extent. It could be assumed that some persons are included in the no-RTW group who had actually partially RTW. Considering the small sample size of the subgroup analyses, the results should be interpreted with caution.

\section{5 | CONCLUSION}

Work-related predictors for shorter time to RTW after stroke were being a qualified worker and working in a larger organization. Male sex predicted a shorter time to RTW. The predictors differed between the sexes, where occupational qualification level was of importance for RTW in men but not in women. For women, the only predictor for shorter time to RTW was physical independency at discharge. Reasons for differences between men and women in work-related factors that influence RTW need to be further investigated to better understand how to support women in the RTW process.

\section{ACKNOWLEDGEMENTS}

We would like to thank $\operatorname{Dr}$ Annelie Inghilesi Larsson for statistical advice. We would also like to thank Dr Kate Bramley-Moore for checking the language of the manuscript.

\section{COMPETING INTERESTS}

The authors have no competing interests to declare.

\section{AUTHORS' CONTRIBUTIONS}

AP worked with study acquisition, study design, data analysis, interpretation of data and first draft of the manuscript. EW worked with data analysis and interpretation of data, HCP worked with data analysis and interpretation of data, and KSS worked with study acquisition, study design and interpretation of data. All the authors were involved in writing the manuscript and revising it critically for important intellectual content. All the authors approved the final version of the article.

\section{ETHICS APPROVAL AND CONSENT TO PARTICIPATE}

The original SALGOT study and the follow-ups with the Social Insurance Agency and Statistics Sweden were all approved by the Regional Ethics Committee in Gothenburg (Dnr: 225-08, T801-10, Dnr: 400-13 and Dnr: T830-15). The participants received information about the research and that it was voluntary to participate at the time of the follow-up questionnaire. According to the Swedish Data Inspection Board, data that are handled within the frame of national quality registers are an exception from the general rule of 
informed consent because it allows improvement of the quality of care and treatment that is of general interest.

\section{AVAILABILITY OF DATA AND MATERIALS}

The data sets analysed during the current study are not publicly available due to ethical restrictions. According to the Swedish regulation http://www.epn.se/en/start/regulations/, the permission to use data is only for what has been applied for and then approved by the Ethical board. Data are available from the authors (contact Professor Katharina S. Sunnerhagen, email: ks.sunnerhagen@neuro. gu.se) upon reasonable request.

\section{ORCID}

Annie Palstam (iD https://orcid.org/0000-0002-7127-213X

Emma Westerlind (iD https://orcid.org/0000-0001-5410-4719

Hanna C. Persson (iD https://orcid.org/0000-0001-8633-3292

Katharina S. Sunnerhagen (iD https://orcid.

org/0000-0002-5940-4400

\section{REFERENCES}

1. Vos T, Abajobir AA, Abbafati C, et al. Global, regional, and national incidence, prevalence, and years lived with disability for 328 diseases and injuries for 195 countries, 1990-2016. Lancet. 2017.

2. Chaker L, Falla A, Lee SJ, et al. The global impact of non-communicable diseases on macro-economic productivity: a systematic review. Eur J Epidemiol. 2015;30(5):357-395.

3. Riksstroke (the Swedish Stroke Resister). Yearly report (Acute-, TIAand 3 month follow-up). 2015. www.riksstroke.org/wp-content/ uploads/2015/12/Strokerapport_AKUT-TIA_LR.pdf.

4. Krishnamurthi R, Feigin V, Forouzanfar $\mathrm{MH}$ et al. Global and regional burden of first-ever ischaemic and haemorrhagic stroke during 1990-2010: findings from the Global Burden of Disease Study 2010. Lancet Glob Health, 2013;1(5):e259-e281.

5. Hannerz H, Holbaek Pedersen B, Poulsen OM, Humle F, Andersen LL. A nationwide prospective cohort study on return to gainful occupation after stroke in Denmark 1996-2006. BMJ Open. 2011;1(2):e000180.

6. Larsen LP, Biering K, Johnsen SP, Andersen G, Hjollund NH. Selfrated health and return to work after first-time stroke. J Rehabil Med. 2016;48(4):339-345.

7. Endo M, Sairenchi T, Kojimahara N, et al. Sickness absence and return to work among Japanese stroke survivors: a 365-day cohort study. BMJ Open. 2016;6(1):e009682.

8. Glader EL, Jonsson B, Norrving B, Eriksson M. Socioeconomic factors' effect on return to work after first stroke. Acta Neurol Scand. 2017;135(6):608-613.

9. Westerlind E, Persson HC, Sunnerhagen KS. Return to Work after a Stroke in Working Age Persons; A Six-Year Follow Up. PLoS ONE. 2017;12(1):e0169759.

10. Edwards JD, Kapoor A, Linkewich E, Swartz RH. Return to work after young stroke: A systematic review. Int J Stroke. 2018;13(3):243-256.
11. Wang YC, Kapellusch J, Garg A. Important factors influencing the return to work after stroke. Work (Reading, Mass). 2014;47(4):553-559.

12. Virtanen M, Ervasti J, Mittendorfer-Rutz E, et al. Work disability before and after a major cardiovascular event: a ten-year study using nationwide medical and insurance registers. Sci Rep. 2017;7(1):1142.

13. Hannerz H, Ferm L, Poulsen OM, Pedersen BH, Andersen LL. Enterprise size and return to work after stroke. J Occup Rehabil. 2012;22(4):456-461.

14. Christiansen $\mathrm{CH}$. The 1999 Eleanor Clarke Slagle Lecture. Defining lives: occupation as identity: an essay on competence, coherence, and the creation of meaning. Am J Occup Ther. 1999;53(6):547-558.

15. Sarre S, Redlich C, Tinker A, Sadler E, Bhalla A, McKevitt C. A systematic review of qualitative studies on adjusting after stroke: lessons for the study of resilience. Disabil Rehabil. 2014;36(9):716-726.

16. Vestling M, Tufvesson B, Iwarsson S. Indicators for return to work after stroke and the importance of work for subjective well-being and life satisfaction. J Rehabil Med. 2003;35(3):127-131.

17. Wolfenden B, Grace M. Returning to work after stroke: a review. Int J Rehabil Res. 2009;32(2):93-97.

18. Roding J, Glader EL, Malm J, Lindstrom B. Life satisfaction in younger individuals after stroke: different predisposing factors among men and women. J Rehabil Med. 2010;42(2):155-161.

19. Ghatnekar O, Persson U, Asplund K, laderE. Costs for stroke in Sweden 2009 and developments since 1997. Int J Technol Assess Health Care. 2014;30(2):203-209.

20. Persson HC, Parziali M, Danielsson A, Sunnerhagen KS. Outcome and upper extremity function within 72 hours after first occasion of stroke in an unselected population at a stroke unit. A part of the SALGOT study. BMC neurol. 2012;12:162.

21. Vikholmen K, Persson HC, Sunnerhagen KS. Stroke treated at a neurosurgical ward: a cohort study. Acta Neurol Scand. 2015;132(5):329-336

22. van Swieten JC, Koudstaal PJ, Visser MC, Schouten HJ, van Gijn J. Interobserver agreement for the assessment of handicap in stroke patients. Stroke. 1988;19(5):604-607.

23. Lindström B, Röding J, Sundelin G. Positive attitudes and preserved high level of motor performance are important factors for return to work in younger persons after stroke: a national survey. J Rehabil Med. 2009;41(9):714-718.

24. Wiemer A, Mölders C, Fischer S, Kawohl W, Rössler W. Effectiveness of medical rehabilitation on return-to-work depends on the interplay of occupation characteristics and disease. J Occup Rehabil. 2017;27(1):59-69.

25. Williams RM, Westmorland M. Perspectives on workplace disability management: a review of the literature. Work (Reading, Mass). 2002;19(1):87-93.

26. Hackett ML, Glozier N, Jan S, Lindley R. Returning to paid employment after stroke: the Psychosocial Outcomes In StrokE (POISE) cohort study. PLoS ONE. 2012;7(7):e41795.

27. Saeki S, Toyonaga T. Determinants of early return to work after first stroke in Japan. J Rehabil Med. 2010;42(3):254-258.

How to cite this article: Palstam A, Westerlind E, Persson HC, Sunnerhagen KS. Work-related predictors for return to work after stroke. Acta Neurol Scand. 2019;139:382-388. https://doi. org/10.1111/ane.13067 